\section{Ecophysiological response and morphological adjustment of Argania spinosa L. Skeels under contrasting climates: case study of marginal populations}

Mohamed Ait Bihi, ${ }^{1}$ Fatima Ain-Lhout, ${ }^{2}$ Abdelhakim Hatimi, ${ }^{1}$ Fadma Fahmi, ${ }^{1}$ Saida Tahrouch ${ }^{1}$

${ }^{1}$ Laboratory of Plant Biotechnology, Faculty of Sciences, Ibn Zohr University, Morocco; ${ }^{2}$ Department of Environment and Life Sciences, Faculty of Applied Sciences, Ibn Zohr University, Morocco

\begin{abstract}
In this paper, we investigated the seasonal physiological performance and morphological adjustment of Argania spinosa growing under contrasting climatic and biogeographic conditions. Two marginal populations were selected in the main distribution area of the species, one at the Northwest and the other one at the South-west. Trees from the North showed a Mediterranean pattern in Photosynthetic performances, exhibiting maximal carbon assimilation during spring and minimum in summer. In contrast, trees from the South showed a different pattern with maximum values recorded in winter and minimum in spring. Photochemical efficiency of PSII results evidenced the absence of damage to PSII in both sites, probably due to an efficient energy dissipation processed by carotenoid pigments. We recorded increased LMA values in the South, which improves drought resistance. Increasing stomatal length and decreasing stomatal density were registered during the drought season in both populations. A. Spinosa is sensitive to changes in the length of drought stress at its Southern limit. The scarcity of rainfall leading to persistent drought has limited the distribution of the species to the banks of dry Wadis and depressions, where it finds some water compensations during summer. In the North, the summer drought severely impacted the species carbon assimilation.
\end{abstract}

\section{Introduction}

For the twenty-first century, global climate observations show the existence of a warming trend, as well as higher frequency and magnitude of drought events. Increasing evidence show that climate extremes will be of larger intensity and frequency under expected climate change. ${ }^{1}$ Several climate forecast models amplify aridity, making North Africa a climate change hotspot with negative impacts on ecological systems. ${ }^{2}$ The challenge in the coming years will be to learn how carbon uptake and growth in species and communities will respond to these changes and how forest management strategies can be improved to alleviate the negative impacts of climate change on forests. ${ }^{3}$

It is well known that vegetation structure, biogeochemical and physiological processes are sensitive to extreme droughts. ${ }^{4}$ The knowledge of the ecosystem's response to periodic drought is essential to understanding their structure and function. ${ }^{5}$ Thus plant adaptations to drought in arid environments are essential for their survival. Under water-limiting conditions, leaves play a critical role in the adaptive mechanism, several strategies are adopted to reduce water losses under a water deficit environment.

The Argan [Argania spinosa (L.) Skeels] is a Moroccan endemic species with a tropical origin. Argan woodlands constitute a specific ecosystem of the South-west of Morocco at the edge of the Saharian Desert. This species plays essential ecological functions and indispensable socio-economical roles in arid and semiarid lands. As a multipurpose tree, $A$. spinosa sustains more than 2.5 million people, significantly alleviating poverty. ${ }^{6,7} \mathrm{In}$ recognition of its local economic and ecological value, the Argan forest is protected by various United Nations entities and designated in 1998 as a biosphere reserve by UNESCO. In 2021, the 10 May was proclaimed the International Day of $A$. spinosa by the General Assembly of the United Nations.

It has been reported that a much larger area than today was covered by dense Argan woodlands, and a boundary contraction of $200 \mathrm{~km}$ has occurred at Northern and Southern limits. ${ }^{8}$ Although at the South limit of the species, precipitations decrease to less than $100 \mathrm{~mm}$, the tree can grow following temporary watercourses (dry Wadis). ${ }^{9}$

The most vulnerable area is at the Southern limit, where A. spinosa ecosystem lost, during the last century, half of its surface area because of biotic and abiotic stress factors. ${ }^{10}$ Conditions become less favorable on the margins than the center of the distribution, owing to increased abiotic stress involving a reduction in population densities ${ }^{11}$

Previous studies have presented useful information concerning the species response to drought, but no studies have
Correspondence: Fatima Ain-Lhout, Campus Universitaire Ait Meloul, Faculté des Sciences Appliquées, Route Nationale N10, BP 6146 Cité Azrou, Ait Melloul 86150, Morocco.

Tel.: +212666021070.

E-mail: fzainlhout@gmail.com.

Key words: Drought; Photosynthesis; Stomatal conductance; Relative water content.

Acknowledgments: This work was supported by internal funding from Ibn Zohr University. The valuable comments of two anonymous reviewers are acknowledged.

Contributions: MAB carried out the fieldwork, laboratory and performed the statistical analysis. He wrote the original draft paper. FAL designed the study, carried out the fieldwork, performed the statistical analysis and helped in writing the manuscript. AH designed the study, contributed to funding acquisition, and revised the initial draft paper. FF carried out the fieldwork, laboratory and revised the initial draft paper. ST designed the study, contributed to funding acquisition, and revised the initial draft paper

Conflict of interest: The authors declare no potential conflict of interest.

Funding: Ibn Zohr University.

Received for publication: 18 October 2021 Accepted for publication: 19 November 2021.

This work is licensed under a Creative Commons Attribution-NonCommercial 4.0 International License (CC BY-NC 4.0).

${ }^{(}{ }_{C}$ Copyright: the Author(s), 2021

Licensee PAGEPress srl, Italy

International Journal of Plant Biology 2021; $12: 9404$ doi:10.4081/pb.2021.9404

been done on the performances of the species at its ecological South-western limit, where extreme environmental conditions are current. ${ }^{12,13}$ At its Southern ecological limit, an assessment of the Argan tree's climate sensitivity is needed to understand and counteract his exposure to the future risks of climate warming. A. spinosa reaches its South-western ecological limit, of its main distribution area, in the Draa Bassin. ${ }^{8}$ At this site, we assume that $A$. spinosa populations will probably be more vulnerable to the expected climate extremes than the Northern located populations. Adaptation to the south marginal habitat may imply some specific changes in species traits.

Here, we investigated the ecophysiological and morphological status of two populations growing under contrasting climatic 
and biogeographic conditions. One of them is located in the North-western part of the species' main distribution area. The other one growing in more arid conditions, at the South-western limit of the main distribution area of the species.

We measured several physiological and morphological parameters to assess both populations. This evaluation will allow us to estimate the consequences of climate change on the future performance of marginal $A$. spinosa populations, growing at the species limit of climatic tolerance.

\section{Materials and methods}

\section{Study areas}

Two experimental sites were chosen, one in the South limit of Argan tree range $\left(29^{\circ} 06^{\prime} 24^{\prime \prime} \mathrm{N} ; 10^{\circ} 06^{\prime} 32^{\prime \prime} \mathrm{W}\right)$, at Northern Guelmim hereafter South, where the trees are grouped along the banks bordering the ephemeral Oued Das. The climate is arid with mild winters due to the proximity of the Atlantic Ocean. Annual rainfall is particularly low, about $118 \mathrm{~mm}$. The other site located South of Smimou village $\left(31^{\circ} 09^{\prime} 10^{\prime \prime} \mathrm{N} ; 9^{\circ} 42^{\prime} 10^{\prime \prime} \mathrm{W}\right)$ called hereafter North, is characterized by a semi-arid climate with annual rainfall not exceeding 350 $\mathrm{mm}$.

\section{Field sampling and analyses}

Ten individuals of each population were randomly marked for the study. Field measurements and sample collection were made on sunny days across two annual cycles from September 2016 to April 2018: summer (September 2016 and July 2017), winter (December 2016 and December 2017), and spring (April 17 and April 2018).

On fully expanded leaves exposed to full sunlight (three leaves per tree. $n=30$ ), the following parameters were measured each season: relative water content (RWC), gas exchange $\left(A_{N}, g_{s}, C i\right)$, maximal photochemical efficiency of photosystem II (Fv/Fm), chlorophyll $a+b$, chlorophyll $a$, chlorophyll $b$ and carotenoid contents, free proline content, leaf mass area (LMA), stomatal density and stomatal length. For pigment and proline analysis, samples from each marked plant were kept refrigerated in individual hermetic plastic bags. Once in the laboratory, they were kept immediately at $-24^{\circ} \mathrm{C}$. For RWC, fresh weight was measured as soon as arriving at the laboratory within the same day.

RWC was determined according to the method described by Slatyer and Shmueli (1967). ${ }^{14} 0.5 \mathrm{~g}$ of fresh leaves were weighted $(\mathrm{FW})$, then floated in cold distilled water for 24 hours to obtain turgid weight (TW). Then the leaves were oven-dried to give the dry weight (DW). Relative water content was calculated by the following formula:

$$
\mathrm{RWC}=\mathrm{FW}-\mathrm{DW} / \mathrm{TW}-\mathrm{DW} \times 100 .
$$

The net photosynthetic rate $\left(\mathrm{A}_{\mathrm{N}}\right)$, stomatal conductance $\left(\mathrm{g}_{\mathrm{s}}\right)$, and sub-stomatal $\mathrm{CO}_{2}$ concentration $\left(\mathrm{C}_{\mathrm{i}}\right)$, were monitored by an infrared gas exchange analyzer (LCiportable, ADC, UK) equipped with a light leaf chamber. The measurements were taken in-situ on three leaves per tree, during a clear sunny day, between 8:00 and 11:00h solar time to avoid midday depression of photosynthesis. The results must be expressed on a projected leaf area basis. Hence, leaves used for gas exchange activity were scanned, and leaf surface was measured using the Mesurim Pro software.

Chlorophyll a fluorescence measurements were carried out at midday on three leaves per plant previously dark-adapted for 20 minutes with a clip holder. The pulseamplitude modulation technique was used via a portable fluorimeter (OSp5+, ADC, UK). ${ }^{15} \mathrm{~A}$ brief saturating pulse was applied, and $\mathrm{F}_{0}$ (initial minimal fluorescence) and $\mathrm{F}_{\mathrm{m}}$ (maximal fluorescence) were recorded. The maximum photochemical efficiency of PSII of dark-adapted leaves was automatically calculated as: $F_{v} / F_{m}=\left(F_{m}-F_{o}\right) / F_{m}$.

Photosynthetic pigments were extracted from each sample with $80 \%$ acetone and determined spectrophotometrically following Lichtenthaler (1987). ${ }^{16}$ The sample absorbance at 470, 646.8, and $663.2 \mathrm{~nm}$ was measured, and total chlorophyll, chlorophyll $a$ and $b$, and carotenoid contents were computed.

Free proline content in leaves was determined by a spectrophotometer according to the Ninhydrin acid method of Bates et al., (1973). ${ }^{17}$ Proline concentration was estimated using L-proline for the standard curve.

Stomatal density was determined as described by Camargo and Marenco (2011), using leaf imprints. ${ }^{18}$ The number of stomata and guard cell length was measured using an ocular micrometer in a light microscope system, 40x objective (Olympus, UK). Imprints were taken from three fully expanded leaves per tree and three samples per leaf.

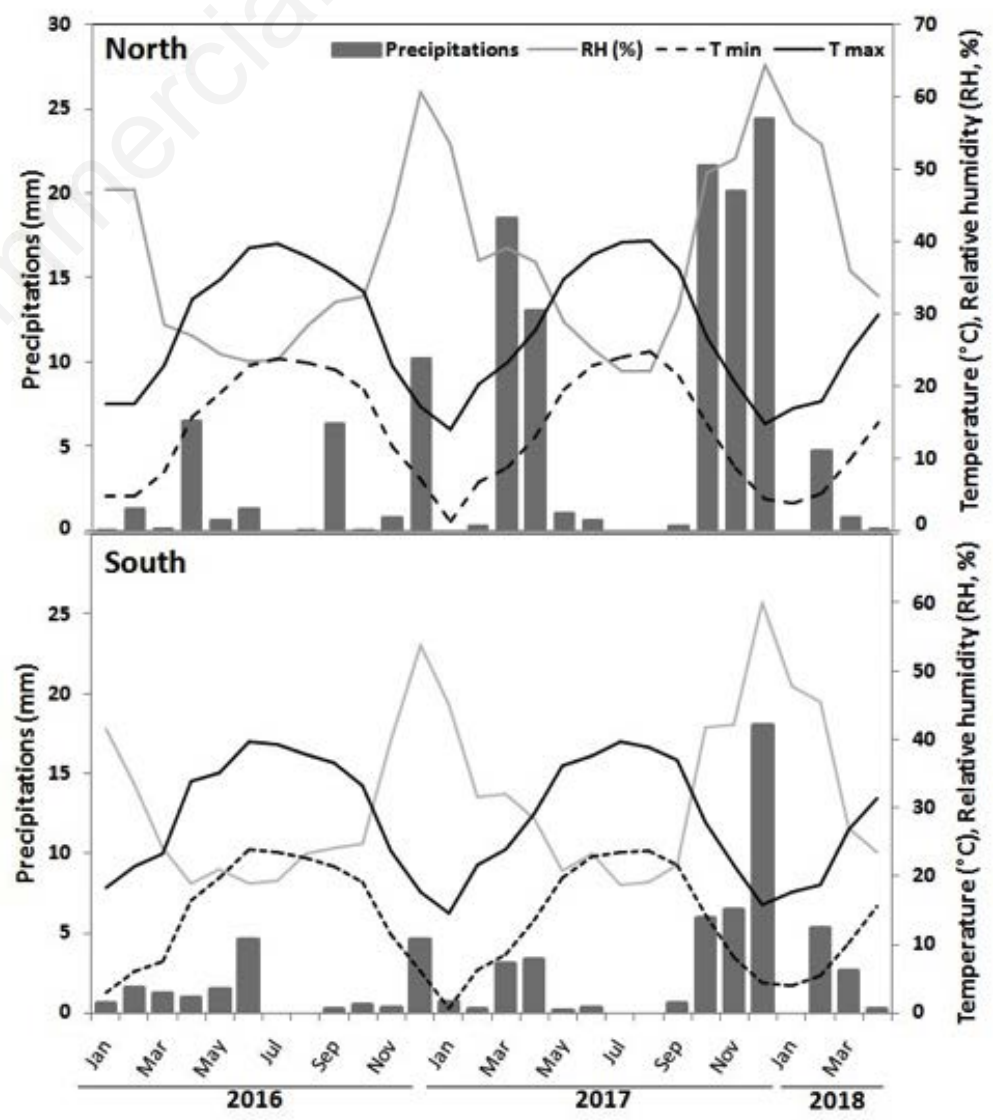

Figure 1 Average maximum $\left(\mathrm{T}_{\max }\right)$ and minimum $\left(\mathrm{T}_{\min }\right)$ monthly air temperature, monthly rainfall and relative humidity $\%(\mathrm{RH})$ during $2016 / 17 / 18$ annual cycles in the two study sites. 
Leaf mass area was determined according to le Maire et al. (2008). ${ }^{19}$ One or two leaves were scanned then measured with the "Mesurim Pro" software. Scanned leaves were oven-dried for 24 hours at $100{ }^{\circ} \mathrm{C}$ before being weighted. Leaf mass area was calculated as the dry leaf mass to leaf surface area ratio $\left(\mathrm{g} \mathrm{m}^{-2}\right)$.

STATISTICA 10 software was used to perform Two-way ANOVAs to assess the effect of season and site (independent variables), on ecophysiological variables (dependent variables). Post-hoc Bonferroni test was used for multiple comparisons of means. The statistical test was considered significant at the $\mathrm{P}<0.05$ level. We contrasted the values of each parameter to detect seasonal differences between sites using Student's t-tests.

\section{Results}

Over the study period, annual precipitation in the North was $27.57 \mathrm{~mm}$ during the 2016/2017 annual cycle and $100.16 \mathrm{~mm}$ during 2017/2018 (Figure 1). In the South, about $15.98 \mathrm{~mm}$ during 2016/2017, and $38.78 \mathrm{~mm}$ during 2017/2018. Both hydrological cycles were exceptionally dry, the first one being the driest $(96 \%$ lower than the annual mean in the North, and $86 \%$ lower in the South). Summer maximal temperature was respectively $45.54^{\circ} \mathrm{C}$ and $44.63^{\circ} \mathrm{C}$ in the North, and $44.56^{\circ} \mathrm{C}$ and $43.34^{\circ} \mathrm{C}$ in the South.

For RWC, ANOVA test results show significant differences between sites, seasons, and site $\mathrm{x}$ season, respectively, $\mathrm{p}<0.05, \mathrm{p}<0.001$, and $\mathrm{p}<0.001$. The population from the North showed a seasonal pattern with maximum values recorded during the wet season and the minimum during summer (Table 1). A similar pattern was recorded in the South, but the decrease in the spring season was more pronounced than in the Northern population. The recorded values reached $69.62 \pm 2.9 \%$ in April 2018.

The net photosynthesis rate $\left(\mathrm{A}_{\mathrm{N}}\right)$ showed a significant seasonal pattern in both sites (Figure 2a). In the North, the highest values were recorded during spring $2018\left(13.58 \pm 1.92 \mu \mathrm{mol} \mathrm{m}^{-2} \mathrm{~s}^{-1}\right)$, and the lowest during summer $2017(2.73 \pm 1.43$ $\mu \mathrm{mol} \mathrm{m} \mathrm{m}^{-2} \mathrm{~s}^{-1}$ ). In the South, the highest values were recorded during winter 2017 $\left(9.22 \pm 2.88 \mu \mathrm{mol} \mathrm{m}^{-2} \mathrm{~s}^{-1}\right)$, and the lowest in spring $2017\left(4.52 \pm 2.14 \mu \mathrm{mol} \mathrm{m} \mathrm{m}^{-2} \mathrm{~s}^{-1}\right)$. A similar pattern was recorded for the stomatal conductance rate ( $g s)$ in both sites (Figure 2b). Concerning sub-stomatal $\mathrm{CO}_{2}$ concentration $(\mathrm{Ci})$, in the South it increased in the summer of both cycles and spring and winter 2017. However, in the North, it increased in winter 2017 (Figure 2c).

Maximum photochemical efficiency $(\mathrm{Fv} / \mathrm{Fm})$ shows no significant differences between sites during the study period (Figure 3). The two populations presented $\mathrm{Fv} / \mathrm{Fm}$ values ranging between 0.7 and 0.77 , hence close to the optimum.

In the North, the minimum total chlorophyll content was recorded in September, after the summer stress, and the maximum values were recorded in April (Table 1). There were significant differences in the seasonal pattern of all photosynthetic pigment parameters $(\mathrm{p}<0.01)$. The carotenoids to total chlorophyll content ratio ( $\mathrm{Car} / \mathrm{Chl})$ increased in summer for both populations. Chlorophyll $a$ to chlorophyll $b$ ratio (Chl $a / b)$ and $\mathrm{Car} / \mathrm{Chl}$ ratio show a significant difference between seasons $(\mathrm{p}<0.001)$, but no difference between stations. Maximum values of $\mathrm{Chl} a / b$ ratio were registered during winter 2016 in both sites (Table 1).

Concerning the seasonal variation of

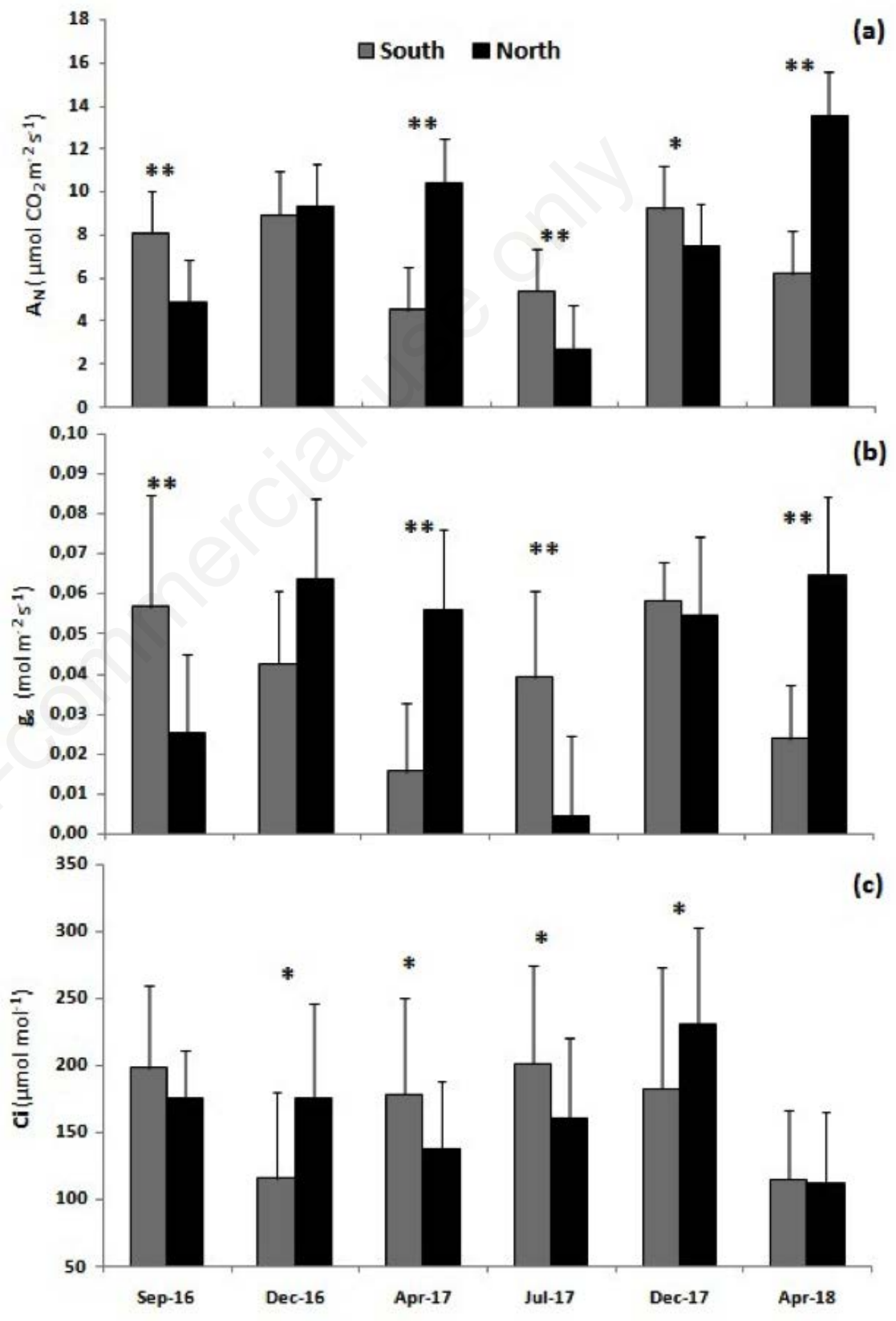

Figure 2. Net photosynthetic rate, $\mathrm{AN}(\mathrm{a})$, stomatal conductance, $\mathrm{g}_{\mathrm{s}}(\mathrm{b})$, and leaf intercellular $\mathrm{CO}_{2}$ concentration $\mathrm{Ci}(\mathrm{c})$ in randomly selected leaves of $A$. spinosa in the North and the South. Values represent mean $\pm \mathrm{SE}, \mathrm{n}=\mathbf{3 0}$ for $\mathrm{A}$, gs, and Ci. Asterisks indicate significance levels for the comparison between the two sites within each season by student's $t$ tests $\left({ }^{* *} \mathbf{P}<0.001 ; * \mathbf{P}<0.05\right)$. 
free proline content in leaves (Table 1), the maximum values were recorded during winter in both sites. The ANOVA test shows significant differences between sites $(p<0.05)$, seasons $(p<0.01)$, and site $x$ season $(\mathrm{p}<0.01)$.

Trees from the North show the highest values of stomatal length during the annual cycle 2016 and 2017 (Figure 4a), and significant differences were registered between the two populations. However, there were no significant differences between the two sites in December 2017 and April 2018. In both populations, the highest values of stomata length were recorded during summer. Concerning stomatal density, no significant differences were recorded between sites except in April 2017 $(p<0.05)$. A seasonal pattern was registered with decreasing values in summer and increasing in the favorable period (Figure 4b).

Over the annual two cycles, the lowest LMA values occurred in the trees from the North population (Table 1). In both sites, the highest values were recorded during September 2016. There was a significant difference between sites $(\mathrm{p}<0.001)$, seasons $(\mathrm{p}<0.001)$, and site $x$ season $(p<0.05)$.

\section{Discussion}

Throughout the study period, all the studied parameters exhibited a significant seasonal variation in both sites. Indeed, several studies have shown adjustments of many physiological and morphological parameters, in response to climatic fluctuations.
Leaf water relations data provide a valuable indication of the capacity of woody species to maintain gas exchange, water use, and growth during the drought of the summer period. ${ }^{20}$ For RWC, the results of the two-way ANOVA analysis showed significant differences between sites, seasons, and site $x$ season $(p<0.05, p<0.001$, $\mathrm{p}<0.001$ ), respectively. The Northern population presented high values of RWC during winter and spring, which is common in Mediterranean species. The lowest values were recorded in summer. However, the population from the South exhibited a different pattern with low values of RWC recorded during spring and summer, sug- gesting that drought conditions begin in the spring.

The photosynthetic performances of $A$. spinosa depend on the season and the station's geographical situation. In the North, maximum rates of $\mathrm{A}_{\mathrm{N}}$ were recorded during spring and minimum values in summer. The main drops in carbon assimilation were due to stomatal closure to avoid water losses. This behavior has been described in most Mediterranean species and is in accordance with previous work on $A$. spinosa. ${ }^{12}$ The population from the South exhibited a different pattern. High values of $\mathrm{Ci}$ and low values of $A_{N}$ were recorded during summer 2017. Otherwise, it has been shown that

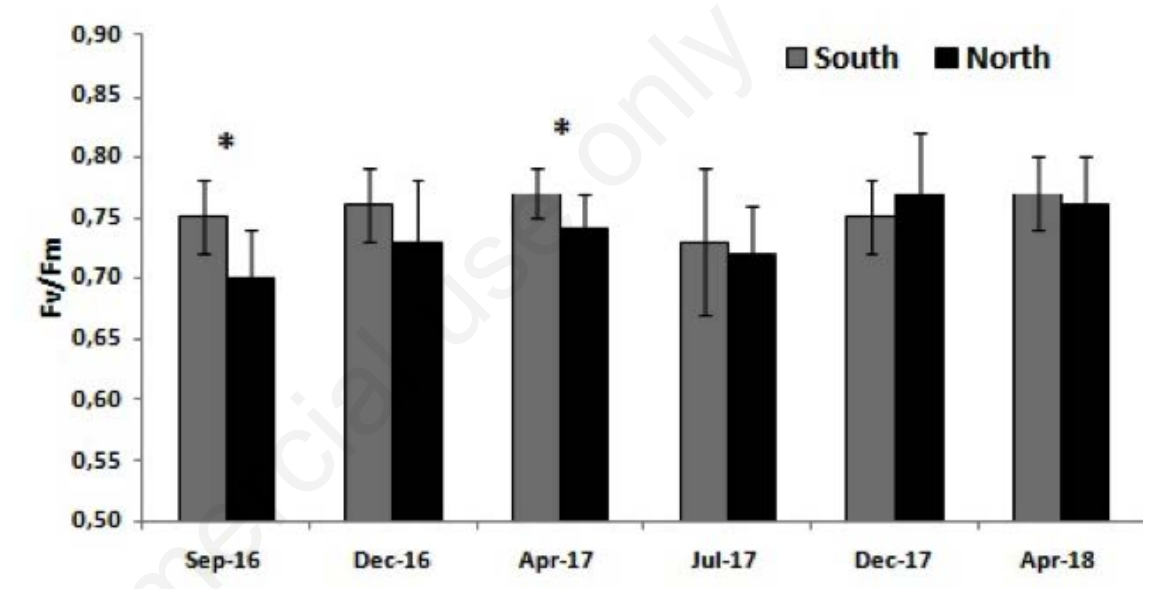

Figure 3. Maximum photochemical efficiency of PSII (Fv/Fm) in randomly selected leaves of $A$. spinosa in the North and the South over the 2016-2017-2018 annual cycles. Values represent mean $\pm S E, n=30$. Asterisks indicate significance levels for the comparison between the two sites within each season by student's $t$-tests $\left(* * P<0.001 ;{ }^{*} \mathbf{P}<0.05\right)$.

Table 1. Relative water content RWC, Total chlorophyll content Chl $a+b\left(\mu \mathrm{mg}^{-1} \mathrm{FM}\right)$, chlorophyll $a / b$ ratio Chl $a / b$, Total carotenoids to total chlorophyll content ratio (Car/Chl), Free proline content $\left(\mathrm{mol} \mathrm{g}^{-1} \mathrm{FM}\right)$, Leaf mass area LMA $\left(\mathrm{g} \mathrm{m}^{-2}\right)$ in randomly selected leaves of $A$. spinosa in the North and the South over the 2016-2017-2018 annual cycles. The standard error is shown. Values represent mean $\pm \mathrm{SE}, \mathrm{n}=30$.

\begin{tabular}{|c|c|c|c|c|c|c|}
\hline \multicolumn{7}{|c|}{ North } \\
\hline RWC & $68.93 \pm 5.43$ & $87.23 \pm 3.15$ & $80.8 \pm 5.14$ & $68.4 \pm 9.34$ & $83.42 \pm 5.32$ & $85.28 \pm 3.18$ \\
\hline Chl $a+b$ & $2.96 \pm 1.05$ & $4.06 \pm 0.85$ & $5.42 \pm 0.94$ & $3.35 \pm 1.31$ & $4.32 \pm 1.12$ & $4.05 \pm 1.20$ \\
\hline Chl $a b$ & $2.35 \pm 0.16$ & $2.98 \pm 1.15$ & $2.06 \pm 0.10$ & $1.71 \pm 0.11$ & $1.99 \pm 0.17$ & $1.95 \pm 0.12$ \\
\hline Car/Chl & $0.23 \pm 0.03$ & $0.21 \pm 0.03$ & $0.16 \pm 0.02$ & $0.22 \pm 0.05$ & $0.19 \pm 0.04$ & $0.23 \pm 0.06$ \\
\hline Proline & $4.3 \pm 0.73$ & $10.8 \pm 7$ & $12.06 \pm 6$ & $5.4 \pm 1.77$ & $16.4 \pm 14.25$ & $7.7 \pm 4.43$ \\
\hline LMA & $99.23 \pm 10$ & $78.76 \pm 11$ & $90.32 \pm 11$ & $84.42 \pm 16$ & $95.58 \pm 11$ & $93.65 \pm 17$ \\
\hline \multicolumn{7}{|c|}{ South } \\
\hline RWC & $72.67 \pm 5.25$ & $78.73 \pm 3.49$ & $74.59 \pm 3.06$ & $69.64 \pm 3.77$ & $84.18 \pm 3.34$ & $69.62 \pm 2.9$ \\
\hline Chl $a+b$ & $1.96 \pm 0.47$ & $4.48 \pm 0.51$ & $5.70 \pm 1.15$ & $3.31 \pm 0.98$ & $4.74 \pm 0.78$ & $4.34 \pm 0.48$ \\
\hline $\mathrm{Chl} a / b$ & $2.61 \pm 0.16$ & $2.96 \pm 0.75$ & $2.11 \pm 0.13$ & $1.84 \pm 0.18$ & $2.15 \pm 0.08$ & $1.99 \pm 0.14$ \\
\hline Car/Chl & $0.28 \pm 0.03$ & $0.19 \pm 0.02$ & $0.16 \pm 0.02$ & $0.24 \pm 0.08$ & $0.18 \pm 0.01$ & $0.21 \pm 0.02$ \\
\hline Proline & $5.3 \pm 3.06$ & $9.6 \pm 3.3$ & $6.8 \pm 2.43$ & $7.6 \pm 1.32$ & $11.4 \pm 5.79$ & $9.3 \pm 2.17$ \\
\hline LMA & $133 \pm 20$ & $110 \pm 13$ & $104 \pm 11$ & $106 \pm 8$ & $107 \pm 17$ & $107 \pm 13$ \\
\hline
\end{tabular}


increasing $\mathrm{Ci}$ indicate that non-stomatal effects mainly cause $A_{N}$ reduction. ${ }^{21}$ This might be due to the decreased pigment content, as well as the inhibition of key enzyme activities in the Calvin cycle, photosynthetic electron transport chain, and RUBISCO activity. ${ }^{22}$ Indeed, a decrease in chlorophyll contents and an increase in total carotenoids to total chlorophyll content ratio were recorded during the summer 2017. This behavior reduces photo-oxidative damage induced by over-excitation. ${ }^{23}$ Carotenoids are an important keynote in heat dissipation of excess excitation energy in the photosystems. That helps prevent superoxide formation in plants receiving excess radiation as photosynthesis decrease under drought conditions. ${ }^{24}$ In our study, the concurrence of high radiation and exceptional drought coincides in both sites, especially in the 2016 cycle. Furthermore, the summer significant increase in the ratio $\mathrm{Car} / \mathrm{Chl}$ indicates the primordial role that the carotenoid pigments play in the energy dissipation process and the protection of the PSII under such harsh summer conditions.

Although autumn 2017 was less dry in the South than in 2016, the subsequent spring, a decrease in $\mathrm{A}_{\mathrm{N}}$ rates was recorded in the presence of a decline in $\mathrm{Ci}$ values. This may be due to the stomatal closure, which prevents irreversible cell dehydration and contributes to the species tolerance strategy. ${ }^{25}$ Surprisingly, no reduction in photosynthetic rate values was registered from spring to summer 2017. Moreover, $A_{N}$ values recorded during summer in trees from the South were significantly higher $(p<0.001)$ than in the North during both cycles. This may probably occur since Argan trees at the Southern margin are distributed along the banks bordering the dry Wadis, where summer flash-floods can occur, providing some water compensation to the trees. This also explains the RWC values recorded in the Southern population, higher than in the North during summer 2017.

Indeed, in the South during winter, adequate sunlight irradiance, better water availability, and mild temperatures have led to increased photosynthetic performances of the species, suggesting that the growing season has been moved towards the winter months. However, they never achieved the performances of the species at the center of its distribution area. For instance, in previous studies, the species exhibited photosynthetic rates in the range of $15 \pm 4.5 \mu \mathrm{mol} \mathrm{m}^{-2}$ $\mathrm{s}^{-1}$ during summer, even more in spring and winter. $^{12}$

Stomatal conductance values clearly show that Argan trees from the North limit their transpiration during summer periods through stomatal closure. The same behavior was observed in the Southern population in April. This trend is in accordance with a previous study on $A$. spinosa, which has shown the existence of a drought-dependent stomatal control. ${ }^{12}$ However, our results are lower than those from the same authors since the gs values recorded even in the most favorable season never exceed $0.064 \pm 0.01 \mathrm{~mol} \mathrm{~m}^{-2} \mathrm{~s}^{-1}$ in the North, and $0.058 \pm 0.01 \mathrm{~mol} \mathrm{~m}^{-2} \mathrm{~s}^{-1}$ in the South. These results could be explained by the drier conditions registered during the study period.

In our study, A. spinosa from the North reduced $\mathrm{Fv} / \mathrm{Fm}$ values slightly during the first annual cycle. On the other hand, trees from the South maintained values ranging from 0.73-0.77 during all the studied periods, even during summer. Considering the optimum values set between 0.7 and 0.8 in normal plants, ${ }^{26}$ our results show values around 0.7 during all the study period, indicating the absence of damage to PSII. This could be attributed to the activation of effective photoprotective mechanisms that dissipate excess energy to prevent the photosynthetic apparatus.
An increase in proline concentration has been registered during winter in both sites. This is in accordance with Díaz Barradas et al. (2010) that associated the increase of proline concentration to the cold temperatures, as the species is described as a thermophilous. ${ }^{12}$ Furthermore, Hare et al. (1998) reported that proline, acting as an electron acceptor, may assist in counteracting photo-inhibitory damage under adverse conditions, even those that do not cause cellular dehydration. ${ }^{27}$ Indeed, in our study, despite the water availability in winter in both sites, cold temperature combined with high radiations may have increased the risk of photoinhibition, that have been avoided by proline accumulation.

Studying drought-adaptation to arid conditions, stomatal density, and aperture and their regulation are of key interest. Stomata range in size from about 10 to 80 $\mu \mathrm{m}$ in length, depending on the species and the environmental conditions. ${ }^{28}$ In our study, both populations exhibited small stomatal size, about 16 to $22 \mu \mathrm{m}$ in length. Hence, this allows them to regulate opening-closure faster and more finely, enabling

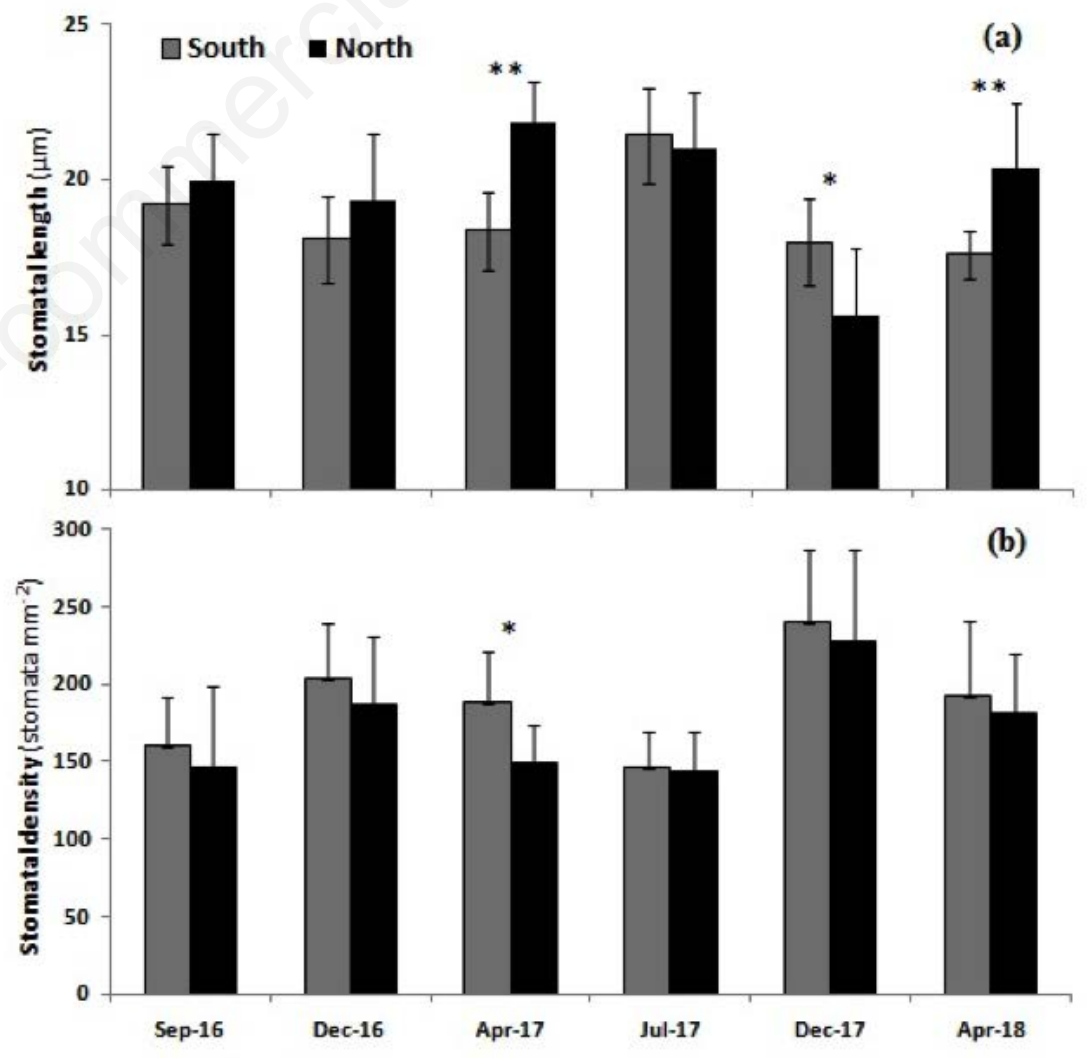

Figure 4. Stomatal length (a) and stomatal density (b) in randomly selected leaves of $A$. spinosa in the North and the South over the 2016-2017-2018 annual cycles. Values represent mean $\pm S E, n=30$. Asterisks indicate significance levels for the comparison between the two sites within each season by student's $t$-tests $\left({ }^{*} \mathbf{P}<0.05\right)$. 
them to respond faster to microclimatic fluctuations during drought, improving leaf water use efficiency. ${ }^{29}$ On the other hand, trees from both sites showed seasonal fluctuations, increasing stomatal length, and decreasing stomatal density during the drought season. A lower stomatal density can reduce stomatal conductance and transpiration rate and be an important structural trait of water conservation. ${ }^{30} \mathrm{~A}$ significant negative relationship was found between stomatal length and StoD in both sites (Data not shown). Suggesting a high regulation by changing stomatal size and density induced by drought conditions.

It is well known that water availability plays a primordial role in modifying leaf structure. The highest LMA values of $A$. spinosa were recorded in the South during all the studied periods. Increasing LMA is interpreted by several authors as an adaptation to dryness; this increases the plant's resistance to physical stresses. ${ }^{31}$ Moreover, higher LMA results in higher leaf compactness which improves drought resistance. When the water potential of the leaf is modified, less elastic leaves lose less water. Therefore, these leaves can extract water from drier soil than more mesophytic leaves. ${ }^{32}$ The maximum LMA values coincided with the exceptional drought of summer 2016, which was extremely dry in both sites.

\section{Conclusions}

In conclusion, $A$. spinosa from both sites showed a conservative water use strategy to cope with the drought. A rigorous stomatal control, with the concurrence of other morpho-physiological adaptations, including an effective photoprotection, allowed the species to balance carbon acquisition and water loss by transpiration and minimizing the exposure of its tissues to stress.

Our results show that the species is sensitive to changes in the length of drought stress at its South limit. We registered a limitation in the carbon assimilation rates starting from the spring season. The scarcity of rainfall leading to persistent water deficit from spring to late summer has limited the distribution of the species in these areas. Indeed, the species is confined along the banks of dry wadis and depressions, where it finds some water compensations during summer stress. In the North, the species maintained a high photosynthetic rates during growing period. However, the summer drought severely impacted carbon assimilation rates.

Given the increasing drought imposed by expected global climate change, the dis- tribution of marginal populations of $A$. spinosa may be constricted. Thus, long-term monitoring of more functional traits of the species is needed to evaluate the ability of the species to persist in marginal ecosystems.

\section{References}

1. Xu C, McDowell NG, Fisher RA, et al. Increasing impacts of extreme droughts on vegetation productivity under climate change. Nat Clim Chang 2019;9:948-53.

2. Tuel A, Eltahir EAB. Why is the Mediterranean a climate change hot spot? J Clim 2020;33:5829-43.

3. Sperlich D, Nadal-Sala D, Gracia C, et al. Gains or Losses in Forest Productivity under Climate Change? The Uncertainty of $\mathrm{CO}_{2}$ Fertilization and Climate Effects. Climate 2020;8:141.

4. Sippel S, Reichstein M, Ma X, et al. Drought, Heat, and the Carbon Cycle: a Review. Curr Clim Change Rep 2018;4:266-86.

5. Vicente-Serrano SM, Gouveia C, Camarero $\mathrm{J}$ et al. Response of vegetation to drought time-scales across global land biomes. Proceedings of the National Academy of Sciences of the United States of America, 2013;110:527.

6. Michon G, Nasi R, Balent G. Public policies and management of rural forests: lasting alliance or fool's dialogue? Ecol Soc 2013;18:30.

7. Lybbert TJ, Magnan N, Aboudrare A. Household and local forest impacts of Morocco's Argan oil bonanza. Environ Dev Econ 2010;15:439-64.

8. Msanda F, El Aboudi A, Peltier JP. Biodiversité et biogéographie de l'Arganeraie marocaine. Cahiers Agriculture 2005;14:357-64.

9. M'Hirit O, Benzyane M, Benchekroum $F$, et al. L'Arganier: une espèce forestière à usages multiples. Mardaga, Belgique. 1998.

10. Tarrier MR, Benzyane M. L'Arganeraie marocaine se meurt: problématique et bio-indication. Secheresse 2003;14:602.

11. Aitken SN, Yeaman S, Holliday JA, et al. Adaptation, migration or extirpation: climate change outcomes for tree populations. Evol Appl 2008;1:95-111.

12. Díaz Barradas MC, Zunzunegui M, Ain-Lhout $F$ et al. Seasonal physiological responses of Argania spinosa tree from Mediterranean to semi-arid climate. Plant Soil 2010;337:217-31.

13. Chakhchar A, Lamaoui M, Aissam S, et al. Physiological and biochemical mechanisms of drought stress tolerance in the Argan tree. In: Ahmad P, Ahanger MA, Singh VP et al., eds. Plant Metabolites and Regulation Under Environmental Stress. Academic Press; 2018.15:311-22.

14. Slatyer RO, Shmueli E. Measurements of Internal Water Status and Transpiration. Irrigation of Agricultural Lands 1967;11:337-53.

15. Schreiber U, Hormann H, Neubauer C, Klughammner C. Assesment of photosystem II photochemical quantum yield by chlorophyll fluorescence quenching analysis. Aust J Plant Physiol 1995;22: 209-20.

16. Lichtenthaler HK. [34]Chlorophylls and carotenoids: Pigments of photosynthetic biomembranes. Methods Enzymol 1987;148:350-82.

17. Bates LS, Waldren RP, Teare ID. Rapid determination of free proline for waterstress studies. Plant Soil 1973;39:205-7.

18. Camargo MAB, Marenco RA. Density, size and distribution of stomata in 35 rainforest tree species in Central Amazonia. J Acta Amazonica 2011;41:205-12.

19. le Maire G, François C, Soudani K, et al. Calibration and validation of hyperspectral indices for the estimation of broadleaved forest leaf chlorophyll content, leaf mass per area, leaf area index and leaf canopy biomass. Remote Sens Environ 2008;112:3846-64.

20. White DA, Turner NC, Galbraith JH. Leaf water relations and stomatal behavior of four allopatric Eucalyptus species planted in Mediterranean Southwestern Australia. Tree Physiol 2000;20:1157-65.

21. Proietti P, Nasini L, Ilarioni L. Photosynthetic behavior of Spanish Arbequina and Italian Maurino olive (Olea europaea L.) cultivars under super-intensive grove conditions. Photosynthetica 2012;50:239-46.

22. Feng J, Shi Q, Wang X, et al. Silicon supplementation ameliorated the inhibition of photosynthesis and nitrate metabolism by cadmium (Cd) toxicity in Cucumis sativus L. Sci Hortic Amst 2010;123:521-30.

23. Gratani L, Varone L. Leaf key traits of Erica arborea L., Erica multiflora L. and Rosmarinus officinalis L. co-occurring in the Mediterranean maquis. Flora 2004;199:58-69.

24. Reddy AR, Chaitanya KV, Vivekanandan M. Drought-induced responses of photosynthesis and antioxidant metabolism in higher plants. J Plant Physiol 2004;161:1189-202. 
25. Larcher W. Physiological plant ecology. Ecophysiology and stress physiology of functional groups. 3th ed. Springer, New York; 2003.

26. Björkman O, Demmig B. Photon yield of $\mathrm{O}_{2}$, evolution and chlorophyll fluorescence characteristics at $77 \mathrm{~K}$ among vascular plants of diverse origins. Planta 1987;170:489-504.

27. Hare PD, Cress WA, Van Staden J. Dissecting the roles of osmolyte accumulation during stress. Plant Cell
Environ 21 1998;6:535-53.

28. Hetherington AM, Woodward FI. The role of stomata in sensing and driving environmental change. Nature 2003;424:901-8.

29. Drake PL, Froend RH, Franks PJ. Smaller, faster stomata: scaling of stomatal size, rate of response, and stomatal conductance. J Exp Bot 2013;64:495505.

30. Dong X, Zhang X. Special stomatal distribution in Sabina vulgaris in relation to its survival in a desert environment. Trees 2000;14:369-75.

31. Zunzunegui M, Ruiz-Valdepeñas E, Sert MA, et al. Field comparison of ecophysiological traits between an invader and a native species in a Mediterranean coastal dune. Plant Physiol Biochem 2020;146:278-86.

32. Niinemets Ü. Global-scale climatic controls of leaf dry mass per area, density, and thickness in trees and shrubs. Ecology 2001;82:453-49. 